\title{
FATORES ASSOCIADOS COM A ESTABILIDADE DE PARAFUSOS E MINI-PLACAS DE TITÂNIO PARA ANCORAGEM ORTODÔNTICA
}

Luis Antonio NERONE; Delson João da COSTA; Paulo Roberto MÜLLER; Rafaela SCARIOT; Nelson Luis Barbosa REBELLATO

Recentemente, parafusos de titânio têm sido utilizados para ancoragem absoluta durante os tratamentos ortodônticos. O objetivo deste trabalho é fazer uma revisão de literatura sobre os fatores que influenciam a estabilidade de mini-implantes e mini-placas de titânio quando utilizados para ancoragem ortodôntica. Diversos tipos de escoras por implantes para ancoragem absoluta têm atraído a atenção dos ortodontistas e que os parafusos de titânio têm as seguintes vantagens: limitação anatômica mínima para a instalação, custo menos elevado, procedimento de simples execução e mínimo desconforto para o paciente. A instalação de parafusos de ancoragem na região posterior dos maxilares apresenta exigências que restringem a posição, inclinação, e profundidade de ancoragem do parafuso. Em contraste, a instalação de mini-placas envolve um procedimento mais complicado e de um custo mais elevado, mas é associado com poucas limitações na posição 3. Concluindo, a estabilidade dos mini-implantes de titânio parece estar relacionada com a ausência de peri-implantite e com o diâmetro do parafuso. O uso de um parafuso de diâmetro maior ou mini-placas está indicado em pacientes portadores de uma grande angulação no plano mandibular. A carga imediata é possível se a força aplicada não superar 2N. 